\title{
Genome sequence of the moderately thermophilic halophile Flexistipes sinusarabici strain (MAS10 ${ }^{\mathrm{T}}$ )
}

\author{
Alla Lapidus ${ }^{1}$, Olga Chertkov ${ }^{1,2}$, Matt Nolan ${ }^{1}$, Susan Lucas ${ }^{1}$, Nancy Hammon ${ }^{1}$, Shweta \\ Deshpande ${ }^{1}$, Jan-Fang Cheng ${ }^{1}$, Roxanne Tapiaa, ${ }^{1,2}$, Cliff Han $^{1,2}$, Lynne Goodwin ${ }^{1,2}$, Sam \\ Pitluck ${ }^{1}$, Konstantinos Liolios ${ }^{1}$, Ioanna Pagani ${ }^{1}$, Natalia Ivanova ${ }^{1}$, Marcel Huntemann ${ }^{1}$, \\ Konstantinos Mavromatis ${ }^{1}$, Natalia Mikhailova ${ }^{1}$, Amrita Pati ${ }^{1}$, Amy Chen ${ }^{3}$, Krishna \\ Palaniappan $^{3}$, Miriam Land ${ }^{1,4}$, Loren Hauser ${ }^{1,4}$, Evelyne-Marie Brambilla ${ }^{5}$, Manfred Rohde ${ }^{6}$, \\ Birte Abt $^{5}$, Stefan Spring ${ }^{5}$, Markus Göker ${ }^{5}$, James Bristow ${ }^{1}$, Jonathan A. Eisen ${ }^{1,7}$, Victor \\ Markowitz ${ }^{4}$, Philip Hugenholtz ${ }^{1,8}$, Nikos C. Kyrpides ${ }^{1}$, Hans-Peter Klenk ${ }^{5 *}$, and Tanja \\ Woyke $^{1}$ \\ ${ }^{1}$ DOE Joint Genome Institute, Walnut Creek, California, USA \\ ${ }^{2}$ Los Alamos National Laboratory, Bioscience Division, Los Alamos, New Mexico, USA \\ ${ }^{3}$ Biological Data Management and Technology Center, Lawrence Berkeley National \\ Laboratory, Berkeley, California, USA \\ ${ }^{4}$ Oak Ridge National Laboratory, Oak Ridge, Tennessee, USA \\ ${ }^{5}$ DSMZ - German Collection of Microorganisms and Cell Cultures GmbH, Braunschweig, \\ Germany \\ ${ }^{6} \mathrm{HZI}$ - Helmholtz Centre for Infection Research, Braunschweig, Germany \\ ${ }^{7}$ University of California Davis Genome Center, Davis, California, USA \\ ${ }^{8}$ Australian Centre for Ecogenomics, School of Chemistry and Molecular Biosciences, The \\ University of Queensland, Brisbane, Australia \\ *Corresponding author: Hans-Peter Klenk
}

Keywords: strictly anaerobic, Gram-negative, non-motile, heterotrophic, moderately thermophilic, marine, brine, Deferribacteraceae, GEBA

Flexistipes sinusarabici Fiala et al. 2000 is the type species of the genus Flexistipes in the family Deferribacteraceae. The species is of interest because of its isolated phylogenetic location in a genomically under-characterized region of the tree of life, and because of its origin from a multiply extreme environment; the Atlantis Deep brines of the Red Sea, where it had to struggle with high temperatures, high salinity, and a high concentrations of heavy metals. This is the fourth completed genome sequence to be published of a type strain of the family Deferribacteraceae. The 2,526,590 bp long genome with its 2,346 protein-coding and 53 RNA genes is a part of the Genomic Encyclopedia of Bacteria and Archaea project.

\section{Introduction}

Strain MAS10 ${ }^{\mathrm{T}}$ (= DSM $4947=$ ATCC 49648) is the type strain of Flexistipes sinusarabici $[1,2]$ which is the type and only species of the genus Flexistipes $[1,2]$. The strain was first isolated from the Atlantis II Deep brines of the Red Sea [1], together with four related isolates. The generic name derives from the Latin words flexus, a bending, turning, winding, and stipes, a branch of tree, stick [1]. The species epithet is derived from the Latin words sinus, a curve or fold in land, a gulf, and arabicus, Arabic, describing the place of isolation [1]. Since the time of its isolation in the late 1980s until now no closely related bacterium (16S rRNA identity $>90 \%$ ) was described. The resistance of the strain to moderate heat, high salt concentrations, and heavy metals [1] should make it an interesting target for extremophile biotechnology. Here we present a summary classification and a set of features for $F$. sinusarabici MAS10 ${ }^{\mathrm{T}}$, together with the description of the complete genomic sequencing and annotation. 


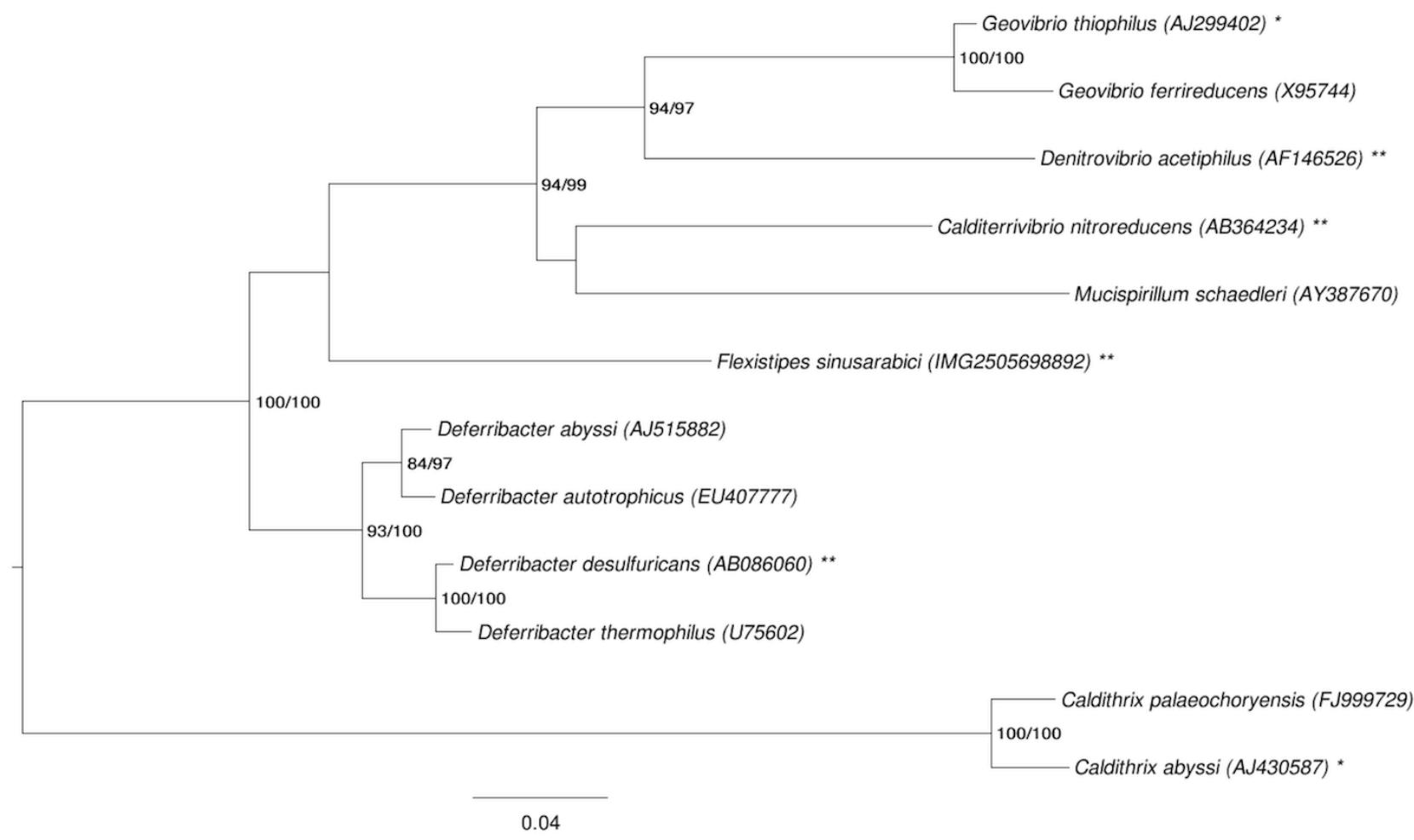

Figure 1. Phylogenetic tree highlighting the position of $F$. sinusarabici relative to the type strains of the other species within the phylum "Deferribacteres". The tree was inferred from 1,459 aligned characters $[7,8]$ of the $16 \mathrm{~S}$ rRNA gene sequence under the maximum likelihood (ML) criterion [9]. Rooting was done initially using the midpoint method [10] and then checked for its agreement with the current classification (Table 1). The branches are scaled in terms of the expected number of substitutions per site. Numbers adjacent to the branches are support values from $250 \mathrm{ML}$ bootstrap replicates [11] (left) and from 1,000 maximum parsimony bootstrap replicates [12] (right) if larger than $60 \%$. Lineages with type strain genome sequencing projects registered in GOLD [13] are labeled with one asterisk, those also listed as 'Complete and Published' with two asterisks [14-16].

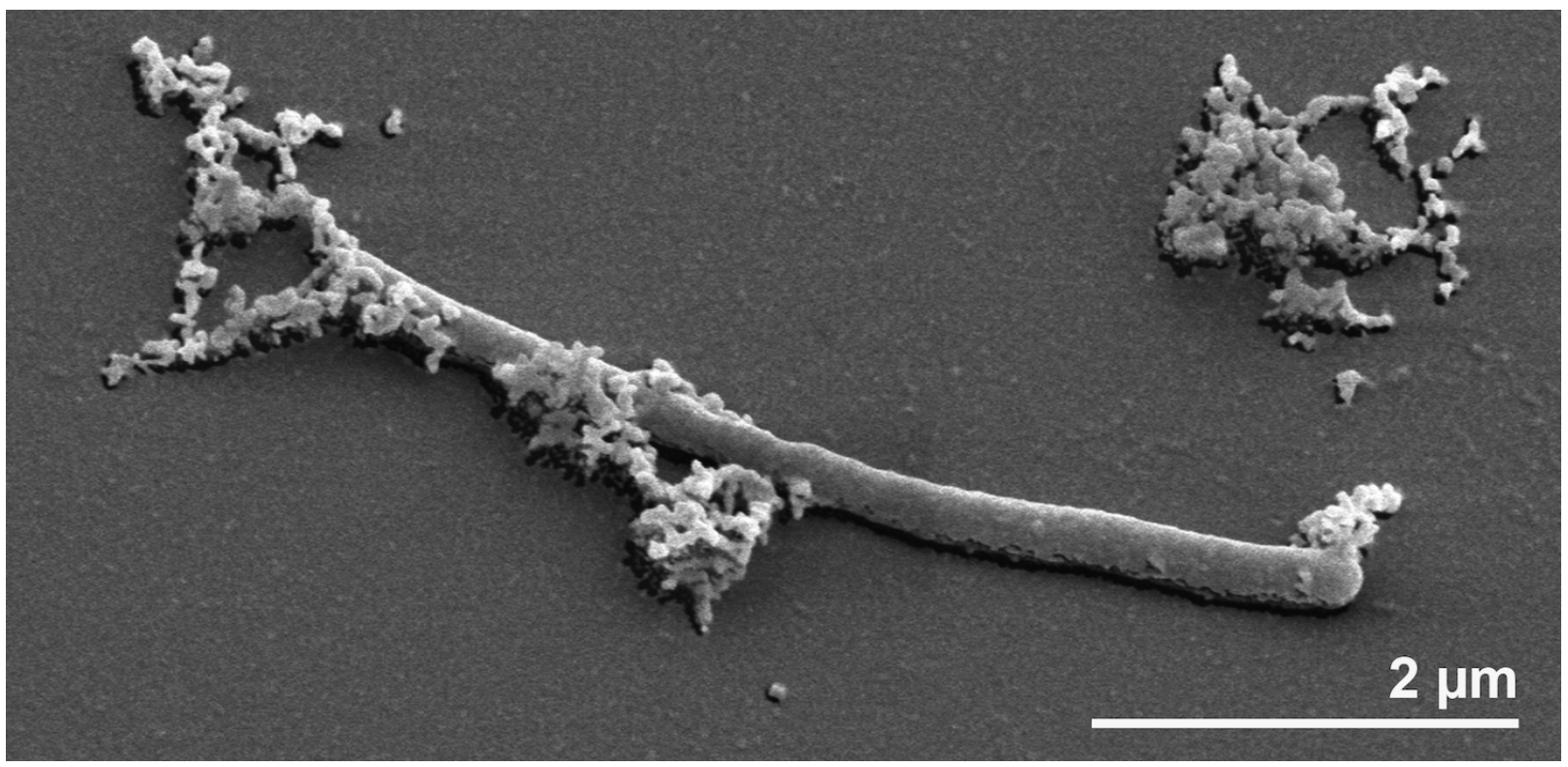

Figure 2. Scanning electron micrograph of $F$. sinusarabici MAS10 ${ }^{\top}$ 


\section{Classification and features}

A representative genomic $16 \mathrm{~S}$ rRNA sequence of strain MAS10 $10^{\mathrm{T}}$ was compared using NCBI BLAST $[3,4]$ under default settings (e.g., considering only the high-scoring segment pairs (HSPs) from the best 250 hits) with the most recent release of the Greengenes database [5] and the relative frequencies of taxa and keywords (reduced to their stem [6]) were determined, weighted by BLAST scores. The most frequently occurring genera were Acidithiobacillus (60.0\%), Deferribacter (26.8\%), Flexistipes (8.2\%), Desulfuromonas (2.2\%) and Calditerrivibrio (1.8\%) (80 hits in total). Regarding the single hit to sequences from members of the species, the average identity within HSPs was $98.0 \%$, whereas the average coverage by HSPs was $96.9 \%$. Among all other species, the one yielding the highest score was Deferribacter abyssi (AJ515881), which corresponded to an identity of $89.7 \%$ and an HSP coverage of $86.4 \%$. (Note that the Greengenes database uses the INSDC (= EMBL/NCBI/DDBJ) annotation, which is not an authoritative source for nomenclature or classification.) The highestscoring environmental sequence was FR744611 ('succession potential reducers nitrate-treated facility determined temperature and nitrate availability production water Halfdan oil field clone PWB039'), which showed an identity of $96.7 \%$ and an HSP coverage of $93.1 \%$. The most frequently occurring keywords within the labels of all environmental samples which yielded hits were 'microbi' (3.9\%), 'acid' (3.4\%), 'sediment' (3.3\%), 'water' (3.0\%) and 'oil' (2.4\%) (170 hits in total). The most frequently occurring keyword within the labels of those environmental samples which yielded hits of a higher score than the highest scoring species was 'avail, determin, facil, field, halfdan, nitrat, nitrate-tr, oil, potenti, product, reduc, success, temperatur, water' $(7.1 \%)$ (1 hit in total). While these keywords fit to the marine environment from which strain MAS10 ${ }^{\mathrm{T}}$ originated, they also point to sediments and oil fields which were so far not considered as habitats for $F$. sinusarabici.

Figure 1 shows the phylogenetic neighborhood of $F$. sinusarabici MAS10 $10^{\mathrm{T}}$ in a $16 \mathrm{~S}$ rRNA based tree. The sequences of the two identical 16S rRNA gene copies in the genome differ by two nucleotides from the previously published 16S rRNA sequence M59231, which contains 25 ambiguous base calls.

Cells of strain MAS10 ${ }^{\mathrm{T}}$ are straight to bent rods, about $0.3 \mu \mathrm{m}$ wide and 4-50 $\mu \mathrm{m}$ long (Figure 2) [1]. F. sinusarabici was described as non-motile [1].
Spore-formation was not observed [1]. MAS10 cells stain Gram-negative, and growth is strictly anaerobic, with the best growth occurring within a temperature range of $45-50^{\circ} \mathrm{C}$ and a minimum doubling time of $81 / 2$ hours [1]. Optimal pH range for the strain is $\mathrm{pH}$ 6-8 [1]. Strain MAS10 ${ }^{\mathrm{T}}$ requires at least $3 \% \mathrm{NaCl}$ for growth, but also grows at salt concentrations as high as $10 \%$ [1]. The organism prefers complex growth substrates such as yeast extract, meat extract, peptone and tryptone, while formate, lactate, citrate, malate, carbohydrate, amino acids and alcohols do not support cell growth [1]. Strain MAS10 ${ }^{\mathrm{T}}$ shows an unusual resistance against the transcription inhibitor rifampicin [1], which is however also commonly found among the spirochetes.

\section{Chemotaxonomy}

The chemotaxonomic data for MAS10 ${ }^{\mathrm{T}}$ is relatively sparse: No information on cell wall structure, quinones or polar lipids is available. The fatty acid composition is dominated by saturated unbranched acids: $\mathrm{C}_{18}(23.3 \%), \mathrm{C}_{16}$ (15.1\%), $\mathrm{C}_{17}$ (12.6\%), with some branched acids iso- $\mathrm{C}_{14}(10.2 \%)$, anteiso- $\mathrm{C}_{15}$ $(10.2 \%)$, iso- $\mathrm{C}_{16}(4.1 \%)$, iso- $\mathrm{C}_{15}(3.6 \%)$, and few unsaturated acids $\mathrm{C}_{18: 1}$ (9.9\%), $\mathrm{C}_{16: 1}(2.8 \%), \mathrm{C}_{17: 1}$ $(2.5 \%)[1]$.

\section{Genome sequencing and annotation Genome project history}

This organism was selected for sequencing on the basis of its phylogenetic position [28], and is part of the Genomic Encyclopedia of Bacteria and Archaea project [29]. The genome project is deposited in the Genome On Line Database [13] and the complete genome sequence is deposited in GenBank. Sequencing, finishing and annotation were performed by the DOE Joint Genome Institute (JGI). A summary of the project information is shown in Table 2.

\section{Growth conditions and DNA isolation}

F. sinusarabici MAS10T, DSM 4947, was grown anaerobically in DSMZ medium 524 (Flexistipes Medium) [30] at $47^{\circ} \mathrm{C}$. DNA was isolated from 0.5-1 $\mathrm{g}$ of cell paste using Jetflex Genomic DNA Purification Kit (GENOMED 600100) following the standard protocol as recommended by the manufacturer, but adding $10 \mu \mathrm{l}$ proteinase $\mathrm{K}$ for one hour extended lysis at $58^{\circ} \mathrm{C}$. DNA is available through the DNA Bank Network [31]. 
Lapidus et al.

Table 1. Classification and general features of $F$. sinusarabici MAS10 ${ }^{\top}$ according to the MIGS recommendations [17] and the NamesforLife database [18].

\begin{tabular}{|c|c|c|c|}
\hline MIGS ID & Property & Term & Evidence code \\
\hline & \multirow{8}{*}{ Current classification } & Domain Bacteria & TAS [19] \\
\hline & & Phylum "Deferribacteres" & TAS $[20,21]$ \\
\hline & & Class "Deferribacteres" & TAS $[22,23]$ \\
\hline & & Order Deferribacterales & TAS $[22,24]$ \\
\hline & & Family Deferribacteraceae & TAS $[22,25]$ \\
\hline & & Genus Flexistipes & TAS $[1,2]$ \\
\hline & & Species Flexistipes sinusarabici & TAS $[1,2]$ \\
\hline & & Type strain MAS10 & TAS [1] \\
\hline & Gram stain & negative & TAS [1] \\
\hline & Cell shape & straight to acutely bent rods & TAS [1] \\
\hline & Motility & non-motile & TAS [1] \\
\hline & Sporulation & none & TAS [1] \\
\hline & Temperature range & $30-53^{\circ} \mathrm{C}$, moderately thermophilic & TAS [1] \\
\hline & Optimum temperature & $45-50^{\circ} \mathrm{C}$ & TAS [1] \\
\hline & Salinity & at least $3 \% \mathrm{NaCl}$, growths with up to $18 \% \mathrm{NaCl}$ & TAS [1] \\
\hline \multirow[t]{3}{*}{ MIGS-22 } & Oxygen requirement & strictly anaerobic & TAS [1] \\
\hline & Carbon source & $\begin{array}{l}\text { complex organic components like yeast extract, meat } \\
\text { extract, peptone, tryptone }\end{array}$ & TAS [1] \\
\hline & Energy metabolism & heterotrophic & TAS [1] \\
\hline MIGS-6 & Habitat & marine, deep brine water & TAS [1] \\
\hline MIGS-15 & Biotic relationship & free-living & TAS [1] \\
\hline \multirow[t]{3}{*}{ MIGS-14 } & Pathogenicity & none & TAS [1] \\
\hline & Biosafety level & 1 & TAS $[26]$ \\
\hline & Isolation & interface between upper brine layer and deep sea water & TAS [1] \\
\hline MIGS-4 & Geographic location & Atlantis II Deep brines, Red Sea & TAS [1] \\
\hline MIGS-5 & Sample collection time & 1987 or before & NAS \\
\hline MIGS-4.1 & Latitude & 21.37 & TAS [1] \\
\hline MIGS-4.2 & Longitude & 38.07 & TAS [1] \\
\hline MIGS-4.3 & Depth & $2,000-2,200 \mathrm{~m}$ & TAS [1] \\
\hline MIGS-4.4 & Altitude & $-2,200-2,200 \mathrm{~m}$ & TAS [1] \\
\hline
\end{tabular}

Evidence codes - TAS: Traceable Author Statement (i.e., a direct report exists in the literature); NAS: Non-traceable Author Statement (i.e., not directly observed for the living, isolated sample, but based on a generally accepted property for the species, or anecdotal evidence). These evidence codes are from the Gene Ontology project [27]. 


\begin{tabular}{lll}
\hline \multicolumn{2}{l}{ Table 2. Genome sequencing project information } \\
\hline MIGS ID & Property & Term \\
\hline MIGS-31 & Finishing quality & Finished \\
MIGS-28 & Libraries used & Four genomic libraries: one 454 pyrosequence standard library, two 454 \\
MIGS-29 & Sequencing platforms & PE libraries (3 kb, 15.5 kb insert size), one Illumina library \\
MIGS-31.2 & Sequencing coverage & $162.0 \times$ Illumina; 37.9 × pyrosequence \\
MIGS-30 & Assemblers & Newbler version 2.3, Velvet version 0.7.63, phrap SPS-4.24 \\
MIGS-32 & Gene calling method & Prodigal 1.4, GenePRIMP \\
& INSDC ID & CP002858 \\
& Genbank Date of Release & June 17, 2011 \\
& GOLD ID & Gc01819 \\
& NCBI project ID & 45817 \\
& Database: IMG-GEBA & 2505679008 \\
MIGS-13 & Source material identifier & DSM 4947 \\
& Project relevance & Tree of Life, GEBA \\
\hline
\end{tabular}

\section{Genome sequencing and assembly}

The genome was sequenced using a combination of Illumina and 454 sequencing platforms. All general aspects of library construction and sequencing can be found at the JGI website [32]. Pyrosequencing reads were assembled using the Newbler assembler (Roche). The initial Newbler assembly consisting of 175 contigs in two scaffolds was converted into a phrap [33] assembly by making fake reads from the consensus, to collect the read pairs in the 454 paired end library. Illumina GAii sequencing data $(489.7 \mathrm{Mb})$ was assembled with Velvet [34] and the consensus sequences were shredded into $2.0 \mathrm{~kb}$ overlapped fake reads and assembled together with the 454 data. The 454 draft assembly was based on 170.4 $\mathrm{Mb} 454$ draft data and all of the 454 paired end data. Newbler parameters are -consed -a 50 -1 350 -g -m -ml 20. The Phred/Phrap/Consed software package [33] was used for sequence assembly and quality assessment in the subsequent finishing process. After the shotgun stage, reads were assembled with parallel phrap (High Performance Software, LLC). Possible mis-assemblies were corrected with gapResolution [32], Dupfinisher [35], or sequencing cloned bridging PCR fragments with subcloning. Gaps between contigs were closed by editing in Consed, by PCR and by Bubble PCR primer walks (J.-F. Chang, unpublished). A total of 605 additional reactions and 15 shatter libraries were necessary to close gaps and to raise the quality of the finished sequence. Illumina reads were also used to correct potential base errors and increase consensus quality using a software Polisher developed at JGI [36]. The error rate of the completed genome sequence is less than 1 in 100,000 . Together, the combination of the Illumina and 454 sequencing platforms provided $199.9 \times$ coverage of the genome. The final assembly contained 248,918 pyrosequence and $395,536,860$ Illumina reads.

\section{Genome annotation}

Genes were identified using Prodigal [37] as part of the Oak Ridge National Laboratory genome annotation pipeline, followed by a round of manual curation using the JGI GenePRIMP pipeline [38]. The predicted CDSs were translated and used to search the National Center for Biotechnology Information (NCBI) non-redundant database, UniProt, TIGR-Fam, Pfam, PRIAM, KEGG, COG, and InterPro databases. Additional gene prediction analysis and functional annotation was performed within the Integrated Microbial Genomes - Expert Review (IMG-ER) platform [39].

\section{Genome properties}

The genome consists of a 2,526,590 bp long circular chromosome with a $\mathrm{G}+\mathrm{C}$ content of $38.3 \%$ (Table 3 and Figure 3). Of the 2,399 genes predicted, 2,346 were protein-coding genes, and 53 RNAs; 85 pseudogenes were also identified. The majority of the protein-coding genes $(75.2 \%)$ were assigned a putative function while the remaining ones were annotated as hypothetical proteins. The distribution of genes into COGs functional categories is presented in Table 4. 
Table 3. Genome Statistics

\begin{tabular}{lrr}
\hline Attribute & Value & \% of Total \\
\hline Genome size (bp) & $2,526,590$ & $100.00 \%$ \\
DNA coding region (bp) & $2,179,830$ & $86.28 \%$ \\
DNA G+C content (bp) & 967,539 & $38.29 \%$ \\
Number of replicons & 1 & \\
Extrachromosomal Elements & 0 & \\
Total genes & 2,399 & $100.00 \%$ \\
RNA genes & 53 & $2.21 \%$ \\
rRNA operons & 2 & \\
Protein-coding genes & 2,346 & $97.79 \%$ \\
Pseudo genes & 85 & $3.54 \%$ \\
Genes with function prediction & 1,803 & $75.16 \%$ \\
Genes in paralog clusters & 242 & $10.09 \%$ \\
Genes assigned to COGs & 1,924 & $80.20 \%$ \\
Genes assigned Pfam domains & 1,978 & $82.45 \%$ \\
Genes with signal peptides & 366 & $15.26 \%$ \\
Genes with transmembrane helices & 579 & $24.14 \%$ \\
CRISPR repeats & 0 & \\
\hline
\end{tabular}

\section{Insight into the genome sequence Comparative genomics}

Lacking an available genome sequence of Deferribacter abyssi, the species yielding the highest score, the following comparative analyses were done with D. desulfuricans [14] (GenBank AP011529, AP011530) and Calditerrivibrio nitroreducens (GenBank CP002347, CP002348) [16], the phylogenetically closest organisms for which a genome sequence was available. The genomes of F. sinusarabici, D. desulfuricans and C. nitroreducens are similar in sizes $(2.5 \mathrm{Mb}, 2.5 \mathrm{Mb}$ and 2.2 $\mathrm{Mb}$, respectively) and have a similar, quite low $\mathrm{G}+\mathrm{C}$ content (38\%, 30\% and 36\%, respectively). Whereas $F$. sinusarabici has no plasmid, D. desulfuricans harbors a $5.9 \mathrm{~kb}$ plasmid; C. nitroreducens contains a $30.8 \mathrm{~kb}$ megaplasmid.

An estimate of the overall similarity between the three genomes was generated with the GGDCGenome-to-Genome Distance Calculator [40,41]. This system calculates the distances by comparing the genomes to obtain HSPs (high-scoring segment pairs) and inferring distances from a set of formulas (1, HSP length / total length; 2 , identities
/ HSP length; 3, identities / total length). Table 5 shows the results of the pairwise comparison between the three genomes.

The comparison of the F. sinusarabici and D. desulfuricans genomes revealed that $5.9 \%$ of the average of both genome lengths are covered with HSPs. The identity within these HSPs was $83.2 \%$, whereas the identity over the whole genome was only $4.9 \%$. Similar results were inferred for $F$. sinusarabici and $C$. nitroreducens (Table 5). The genomes of $D$. desulfuricans and $C$. nitroreducens show a significantly higher degree of similarity with $9.9 \%$ of the average of both genomes are covered with HSPs of $83.3 \%$ identity. The identity over the whole length of the genomes was $8.3 \%$. These values corroborate the relationship between the three organisms as shown in the $16 \mathrm{~S}$ rRNA-based phylogenetic tree in Figure 1, as there is no bootstrap support that $F$. sinusarabici is closer related to either C. nitroreducens or D. desulfuricans. 


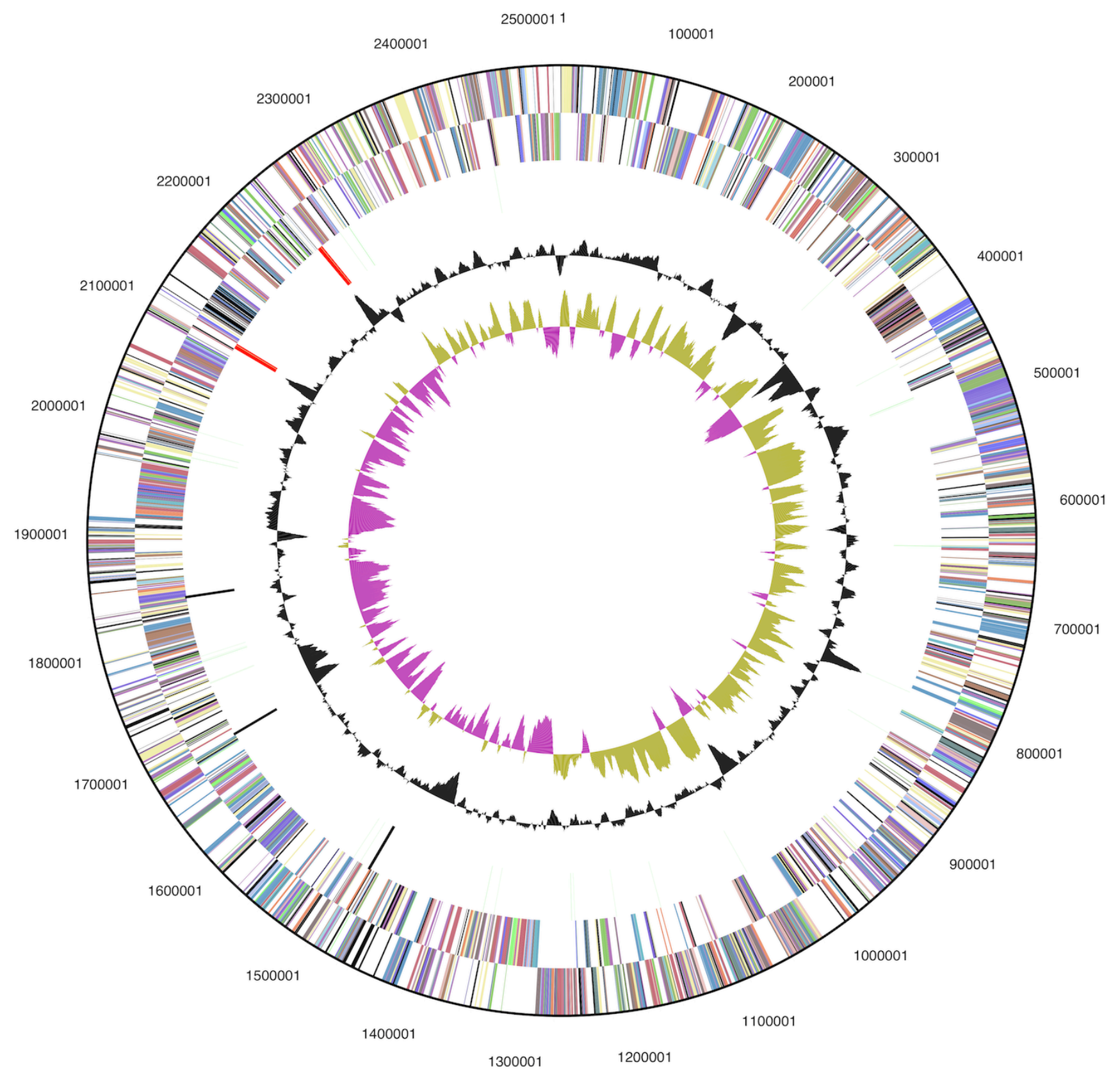

Figure 3. Graphical circular map of the chromosome. From outside to the center: Genes on forward strand (color by COG categories), Genes on reverse strand (color by COG categories), RNA genes (tRNAs green, rRNAs red, other RNAs black), GC content, GC skew.

The fraction of shared genes in the three genomes is shown in a Venn diagram (Figure 4). The numbers of pairwise shared genes were calculated with the phylogenetic profiler function of the IMG/ER platform [33]. The homologous genes within the genomes were detected with a maximum E-value of $10^{-5}$ and a minimum identity of $30 \%$. Roughly $61 \%$ of all genes in the genomes (1,400 genes) are shared by all three genomes, with about equal numbers of genes (224 and 246) shared on a pairwise basis by $F$. sinusarabici and $D$. desulfuricans or by D. desulfuricans and C. nitroreducens, respectively, and to the exclusion of the third genome. Within the 567 unique genes of $F$. sinusarabici that have no detectable homologs in the genomes of $D$. desulfuricans and $C$. nitroreducens (under the sequence similarity thresholds used for the comparison) the 86 genes (3.7\% based on the whole gene number) encoding transposases appear to be noteworthy. 
Table 4. Number of genes associated with the general COG functional categories

\begin{tabular}{crrl}
\hline Code & value & \%age & Description \\
\hline J & 145 & 7.0 & Translation, ribosomal structure and biogenesis \\
A & 1 & 0.1 & RNA processing and modification \\
K & 84 & 4.0 & Transcription \\
L & 205 & 9.8 & Replication, recombination and repair \\
B & 2 & 0.1 & Chromatin structure and dynamics \\
D & 21 & 1.0 & Cell cycle control, cell division, chromosome partitioning \\
Y & 0 & 0.0 & Nuclear structure \\
V & 26 & 1.3 & Defense mechanisms \\
T & 115 & 5.5 & Signal transduction mechanisms \\
M & 135 & 6.5 & Cell wall/membrane/envelope biogenesis \\
N & 36 & 1.7 & Cell motility \\
Z & 0 & 0.0 & Cytoskeleton \\
W & 0 & 0.0 & Extracellular structures \\
U & 62 & 3.0 & Intracellular trafficking, secretion, and vesicular transport \\
O & 81 & 3.9 & Posttranslational modification, protein turnover, chaperones \\
C & 174 & 8.3 & Energy production and conversion \\
G & 66 & 3.2 & Carbohydrate transport and metabolism \\
E & 198 & 9.5 & Amino acid transport and metabolism \\
F & 52 & 2.5 & Nucleotide transport and metabolism \\
H & 115 & 5.5 & Coenzyme transport and metabolism \\
I & 60 & 2.9 & Lipid transport and metabolism \\
P & 86 & 4.1 & Inorganic ion transport and metabolism \\
Q & 32 & 1.5 & Secondary metabolites biosynthesis, transport and catabolism \\
R & 246 & 11.8 & General function prediction only \\
\hline & 145 & 7.0 & Function unknown \\
\hline & 475 & 19.8 & Not in COGs \\
\hline & & & \\
S & & &
\end{tabular}

Table 5. Pairwise comparison of $F$. sinusarabici, D. desulfuricans and C. nitroreducens using the GGDC-Calculator.

\begin{tabular}{ccc}
$\begin{array}{c}\text { 1, HSP length } \\
\text { /total length [\%] }\end{array}$ & $\begin{array}{c}2 \text {, identities /HSP } \\
\text { length [\%] }\end{array}$ & $\begin{array}{c}\text { 3, identities } \\
\text { /total length [\%] }\end{array}$ \\
\hline
\end{tabular}

\begin{tabular}{lllll} 
F. sinusarabici & D. desulfuricans & 5.9 & 83.2 & 4.9 \\
F. sinusarabici & C. nitroreducens & 5.1 & 83.3 & 4.3 \\
D. desulfuricans & C. nitroreducens & 9.9 & 83.3 & 8.3 \\
\hline
\end{tabular}


A remarkable difference between the compared organisms is their motility. Whereas $F$. sinusarabi$c i$ is described to be non-motile, $D$. desulfuricans is motile by twitching [14] and C. nitroreducens is also described to be motile [16]. The mechanism of twitching motility is still unknown but it is thought that moving across surfaces is caused by extension and retraction of type IV pili. A set of genes that is responsible for twitching motility was identified in several organisms; in Pseudomonas aeruginosa a gene cluster involved in pilus biosynthesis and twitching motility was characterized, the gene products of this gene cluster show a high degree of sequence similarity to the chemotaxis (che) proteins of enterics and the gliding bacterium Myxococcus xanthus [42]. A closer look into the genome sequences of $F$. sinusarabici, $D$. desulfuricans and $C$. nitroreducens revealed the presence of different gene sets coding for chemotaxis proteins. In contrast to $D$. desulfuricans and $C$. nitroreducens, $F$. sinusarabici lacks four che genes (cheB, che $\mathrm{R}$, cheV, cheW). In P. aeruginosa a mutation in the pill gene, a homolog to $c h e W$, lead to a blocking of pilus production [42]. It can be assumed that the missing cheW gene in $F$. sinusarabici might be responsible for the non-motility of the cells, despite the rather large number of 36 genes annotated in the cell motility category of table 4.
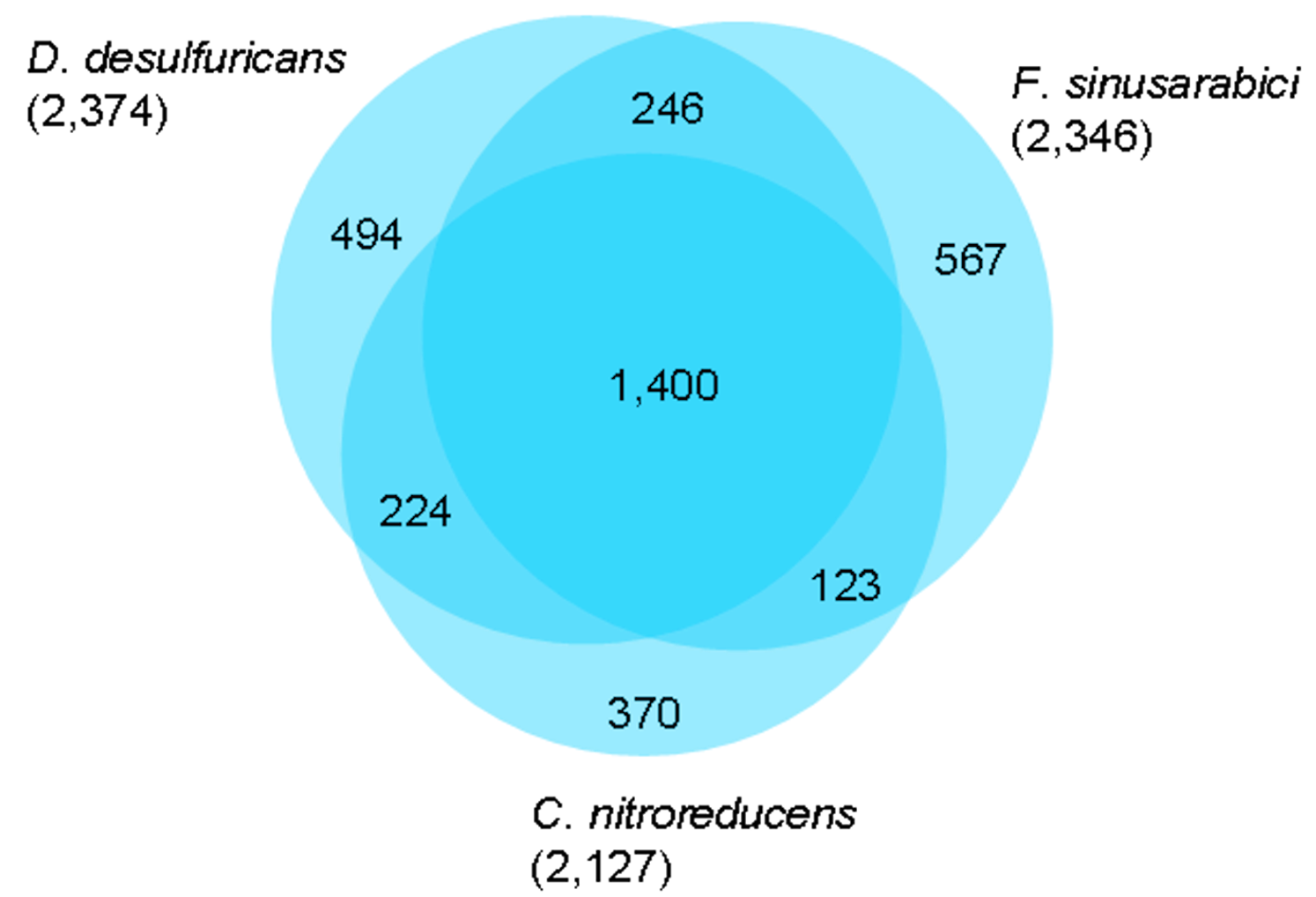

Figure 4. Venn diagram depicting the intersections of protein sets (total number of derived protein sequences in parentheses) of $F$. sinusarabici, D. desulfuricans and C. nitroreducens.

\section{Acknowledgements}

We would like to gratefully acknowledge the help of Maren Schröder (DSMZ) for growing $F$. sinusarabici cultures. This work was performed under the auspices of the US Department of Energy's Office of Science, Biological and Environmental Research Program, and by the University of California, Lawrence Berkeley National Laboratory under contract No. DE-AC02-05CH11231,
Lawrence Livermore National Laboratory under Contract No. DE-AC52-07NA27344, and Los Alamos National Laboratory under contract No. DE-AC0206NA25396, UT-Battelle and Oak Ridge National Laboratory under contract DE-AC05-000R22725, as well as German Research Foundation (DFG) INST 599/1-2. 


\section{References}

1. Fiala G, Woese CR, Langworthy TA, Stetter KO. Flexistipes sinusarabici a novel genus and species of eubacteria occurring in the Atlantis II Deep brines of the Red Sea. Arch Microbiol 1990; 154:120-126. doi:10.1007/BF00423320

2. Validation List No. 75. Int / Syst Evol Microbiol 2000; 50:1415-1417. PubMed doi:10.1099/00207713-50-4-1415

3. Altschul SF, Gish W, Miller W, Myers EW, Lipman DJ. Bascic local alignment search tool. J Mol Biol 1990; 215:403-410. PubMed

4. Korf I, Yandell M, Bedell J. BLAST, O'Reilly, Sebastopol, 2003.

5. DeSantis TZ, Hugenholtz P, Larsen N, Rojas M, Brodie EL, Keller K, Huber T, Dalevi D, Hu P, Andersen GL. Greengenes, a chimera-checked $16 \mathrm{~S}$ rRNA gene database and workbench compatible with ARB. Appl Environ Microbiol 2006; 72:5069-5072. PubMed doi:10.1128/AEM.03006-05

6. Porter MF. An algorithm for suffix stripping. Program: electronic library and information systems 1980; 14:130-137.

7. Castresana J. Selection of conserved blocks from multiple alignments for their use in phylogenetic analysis. Mol Biol Evol 2000; 17:540-552. PubMed

8. Lee C, Grasso C, Sharlow MF. Multiple sequence alignment using partial order graphs. Bioinformatics 2002; 18:452-464. PubMed doi:10.1093/bioinformatics/18.3.452

9. Stamatakis A, Hoover P, Rougemont J. A rapid bootstrap algorithm for the RAxML Web servers. Syst Biol 2008; 57:758-771. PubMed doi:10.1080/10635150802429642

10. Hess PN, De Moraes Russo CA. An empirical test of the midpoint rooting method. Biol / Linn SoC Lond 2007; 92:669-674. doi:10.1111/j.1095$\underline{8312.2007 .00864 . x}$

11. Pattengale ND, Alipour M, Bininda-Emonds ORP, Moret BME, Stamatakis A. How many bootstrap replicates are necessary? Lect Notes Comput Sci 2009; 5541:184-200. doi:10.1007/978-3-64202008-7_13

12. Swofford DL. PAUP*: Phylogenetic Analysis Using Parsimony (*and Other Methods), Version 4.0 b10. Sinauer Associates, Sunderland, 2002.

13. Liolios K, Chen IM, Mavromatis K, Tavernarakis $\mathrm{N}$, Hugenholtz P, Markowitz VM, Kyrpides NC.
The Genomes On Line Database (GOLD) in 2009: status of genomic and metagenomic projects and their associated metadata. Nucleic Acids Res 2010; 38:D346-D354. PubMed doi:10.1093/nar/gkp848

14. Takaki Y, Shimamura S, Nakagawa S, Fukuhara $Y$, Horikawa H, Ankai A, Harada T, Hosoyama A, Oguchi A, Fukui S, et al. Bacterial lifestyle in a deep-sea hydrothermal vent chimney revealed by the genome sequence of the thermophilic bacterium Deferribacter desulfuricans SSM1. DNA Res 2010; 17:123-137. PubMed doi:10.1093/dnares/dsq005

15. Kiss H, Lang E, Lapidus A, Copeland A, Nolan M, Glavina Del Rio T, Chen F, Lucas S, Tice H, Cheng JF, et al. Complete genome sequence of Denitrovibrio acetiphilus tye strain $\left(\mathrm{N} 2460^{\top}\right)$. Stand Genomic Sci 2010; 2:270-279. PubMed doi:10.4056/sigs.892105

16. Pitluck S, Sikorski J, Zeytun A, Lapidus A, Nolan M, Lucas S, Hammon N, Deshpande S, Cheng JF, Tapia $\mathrm{R}$, et al. Complete genome sequence of Calditerrivibrio nitroreducens type strain (Yu37$1^{\top}$ ). Stand Genomic Sci 2011; 4:54-62. PubMed doi:10.4056/sigs.1523807

17. Field D, Garrity G, Gray T, Morrison N, Selengut J, Sterk P, Tatusova T, Thomson N, Allen MJ, Angiuoli SV, et al. The minimum information about a genome sequence (MIGS) specification. Nat Biotechnol 2008; 26:541-547. PubMed doi:10.1038/nbt1360

18. Garrity G. NamesforLife. BrowserTool takes expertise out of the database and puts it right in the browser. Microbiol Today 2010; 37:9.

19. Woese CR, Kandler O, Wheelis ML. Towards a natural system of organisms: proposal for the domains Archaea, Bacteria, and Eucarya. Proc Natl Acad Sci USA 1990; 87:4576-4579. PubMed doi:10.1073/pnas.87.12.4576

20. Garrity GM, Holt JG. Phylum BIX. Deferribacteres phy. nov. In: Garrity GM, Boone DR, Castenholz RW (eds), Bergey's Manual of Systematic Bacteriology, Second Edition, Volume 1, Springer, New York, 2001, p. 465.

21. Jumas-Bilak E, Roudière $L$, Marchandin H. Description of 'Synergistetes' phyl. nov. and emended description of the phylum 'Deferribacteres' and of the family Syntrophomonadaceae, phylum 'Firmicutes'. Int I Syst Evol Microbiol 2009; 59:1028-1035. PubMed doi:10.1099/ijs.0.006718-0 
22. List Editor. Validation List no. 85. Validation of publication of new names and new combinations previously effectively published outside the IJSEM. Int J Syst Evol Microbiol 2002; 52:685-690. PubMed doi:10.1099/ijs.0.02358-0

23. Huber H, Stetter KO. Class I. Deferribacteres class. nov. In: Garrity GM, Boone DR, Castenholz RW (eds), Bergey's Manual of Systematic Bacteriology, Second Edition, Volume 1, Springer, New York, 2001, p. 465.

24. Huber H, Stetter KO. Order I. Deferribacterales ord. nov. In: Garrity GM, Boone DR, Castenholz RW (eds), Bergey's Manual of Systematic Bacteriology, Second Edition, Volume 1, Springer, New York, 2001, p. 465.

25. Huber H, Stetter KO. Family I. Deferribacteraceae fam. nov. In: Garrity GM, Boone DR, Castenholz RW (eds), Bergey's Manual of Systematic Bacteriology, Second Edition, Volume 1, Springer, New York, 2001, p. 465-466.

26. BAuA. Classification of bacteria and archaea in risk groups. TRBA 2005; 466:190.

27. Ashburner M, Ball CA, Blake JA, Botstein D, Butler H, Cherry JM, Davis AP, Dolinski K, Dwight SS, Eppig JT, et al. Gene Ontology: tool for the unification of biology. Nat Genet 2000; 25:25-29. $\underline{\text { PubMed doi:10.1038/75556 }}$

28. Klenk HP, Göker M. En route to a genome-based classification of Archaea and Bacteria? Syst Appl Microbiol 2010; 33:175-182. PubMed doi:10.1016/j.syapm.2010.03.003

29. Wu D, Hugenholtz P, Mavromatis K, Pukall R, Dalin E, Ivanova NN, Kunin V, Goodwin L, Wu $M$, Tindall BJ, et al. A phylogeny-driven genomic encyclopaedia of Bacteria and Archaea. Nature 2009; 462:1056-1060. PubMed doi:10.1038/nature08656

30. List of growth media used at DSMZ: http://www.dsmz.de/microorganisms/media_list.p hp.

31. Gemeinholzer B, Dröge G, Zetzsche H, Haszprunar G, Klenk HP, Güntsch A, Berendsohn WG, Wägele JW. The DNA Bank Network: the start from a German initiative. Biopreservation and Biobanking 2011; 9:51-55. doi:10.1089/bio.2010.0029

32. The DOE Joint Genome Institute. http://www.jgi.doe.gov
33. Phrap and Phred for Windows. MacOS, Linux, and Unix. http://www.phrap.com

34. Zerbino DR, Birney E. Velvet: algorithms for de novo short read assembly using de Bruijn graphs. Genome Res 2008; 18:821-829. PubMed doi:10.1101/gr.074492.107

35. Han C, Chain P. Finishing repeat regions automatically with Dupfinisher. In: Proceeding of the 2006 international conference on bioinformatics \& computational biology. Arabnia HR, Valafar $\mathrm{H}$ (eds), CSREA Press. June 26-29, 2006: 141-146.

36. Lapidus A, LaButti K, Foster B, Lowry S, Trong S, Goltsman E. POLISHER: An effective tool for using ultra short reads in microbial genome assembly and finishing. AGBT, Marco Island, FL, 2008.

37. Hyatt D, Chen GL, LoCascio PF, Land ML, Larimer FW, Hauser LJ. Prodigal: prokaryotic gene recognition and translation initiation site identification. BMC Bioinformatics 2010; 11:119. $\underline{\text { PubMed doi:10.1186/1471-2105-11-119 }}$

38. Pati A, Ivanova NN, Mikhailova N, Ovchinnikova G, Hooper SD, Lykidis A, Kyrpides NC. GenePRIMP: a gene prediction improvement pipeline for prokaryotic genomes. Nat Methods 2010; 7:455-457. PubMed doi:10.1038/nmeth.1457

39. Markowitz VM, Ivanova NN, Chen IMA, Chu K, Kyrpides NC. IMG ER: a system for microbial genome annotation expert review and curation. Bioinformatics 2009; 25:2271-2278. PubMed doi:10.1093/bioinformatics/btp393

40. Auch AF, von Jan M, Klenk HP, Göker M. Digital DNA-DNA hybridization for microbial species delineation by means of genome-to-genome sequence comparison. Stand Genomic Sci 2010; 2:117-134. PubMed doi:10.4056/sigs.531120

41. Auch AF, Klenk HP, Göker M. Standard operating procedure for calculating genome-to-genome distances based on high-scoring segment pairs. Stand Genomic Sci 2010; 2:142-148. PubMed doi:10.4056/sigs.541628

42. Darzins A. Characterization of a Pseudomonas aeruginosa gene cluster involved in pilus biosynthesis and twitching motility: sequence similarity to the chemotaxis proteins of enterics and the gliding bacterium Myxococcus xanthus. Mol Microbiol 1994; 11:137-153. PubMed doi:10.1111/j.1365-2958.1994.tb00296.x 